\title{
Comparative analysis of sticky SGA costs and cost of goods sold: Evidence from Tehran Stock Exchange
}

\author{
Majid Zanjirdar $^{\mathrm{a}}$, Zahra Madahi ${ }^{\mathbf{b}^{*}}$ and Parvaneh Khaleghi Kasbi ${ }^{\mathrm{b}}$
}

\section{H R O N I C L E}

\section{Article history:}

Received October 28, 2013

Received in revised format

20 November 2013

Accepted 12 January 2014

Available online

January 152014

Keywords:

Sticky Costs

Cost Behavior

SGA Cost

Cost of Goods Sold

Tehran Stock Exchange

\section{A B S T R A C T}

One of the primary assumptions in accounting industries is to expect an increase (decrease) in cost of production is proportion to increase (decrease) in sales revenue. However, there are some evidences that the cost of production does not decrease with the same trend as revenue decreases. This phenomenon is called sticky behavior since the cost of production in not reduced as the sales decreases especially in operating as well as administration department. In this paper, we present an empirical investigation to study sticky behavior on 70 selected firms from Tehran Stock Exchange over the period 2002-2011. The results indicate that sales and general administration cost (SGA) as well as the costs of sold goods strongly have sticky behaviors.

\section{Introduction}

One of the primary assumptions in accounting industries is to expect an increase (decrease) in cost of production proportionally increases (decreases) the sales revenue. However, there are some evidences that the cost of production does not decrease as revenue decreases. This phenomenon is called sticky behavior since the cost of production in not reduced as the sales decreases especially in operating as well as administration department (Balakrishnan et al., 2008; Davis \& Hamilton, 2003; He et al., 2010). Anderson et al. (2003), for instance, studied whether different expenses are "sticky"- that is, whether various cost components increase more when activity rises than they decrease when activity cools down by an equivalent amount. They reported, for 7,629 firms over 20 years, that selling, general, and administrative (SG\&A) expenses increase on average $0.55 \%$ per $1 \%$ increase in sales but decrease only $0.35 \%$ per $1 \%$ decrease in sales. Their analysis compared the traditional model of cost *Corresponding author. Tel: +98-09183498192

E-mail addresses: Zahramadahi@yahoo.com (Z. Madahi) 
behavior in which costs could move proportionately with changes in activity with an alternative model in which sticky costs occur because managers deliberately adjust the resources committed to activities.

Banker and Chen (2006) evaluated the descriptive validity of the cost behavior model for profit analysis. They reported that earnings forecast errors based on their model had bigger relative information content than forecast errors based on the two alternative models based on financial statement information in describing abnormal stock returns.

Chen et al. (2012) investigated the agency problem, corporate governance, and the asymmetrical behavior of selling, general, and administrative costs. Noreen and Soderstrom (1997) reported that costing systems, such as activity-based costing, that assume expenses were proportional to activity, would grossly overstate relevant (i.e., incremental) overhead costs for decision-making and performance evaluation purposes.

Wiess (2010) investigated how firms' asymmetric cost behavior affects analysts' earnings forecasts, primarily the accuracy of analysts' consensus earnings forecasts. Results indicate that firms with stickier cost behavior have less accurate analysts' earnings forecasts than firms with less sticky cost behavior. He reported that cost stickiness affects analysts' coverage priorities and investors seem to consider sticky cost behavior in forming their beliefs about the value of firms. The study integrated a typical management accounting research topic, cost behavior, with three standard financial accounting topics.

Anderson et al. (2007) estimated an earnings prediction model and reported that future earnings were positively associated with changes in the SG\&A cost ratio in periods in which revenue declines, inconsistent with traditional interpretation of SG\&A cost changes. In addition, in their survey, abnormal positive returns could be earned on portfolios formed by going long on firms with high increases in the SG\&A cost ratio

\section{The proposed study}

This paper presents an empirical investigation to study sticky behavior on 70 selected firms from Tehran Stock Exchange over the period 2002-2011. The selection process considers the following criteria,

1. The shares of the firm must be actively traded on stock exchange and all necessary information must be disclosed regularly through official agencies.

2. All firms must have the same fiscal year ending March.

3. The study does not include the information of holding, financial firms, banks and construction firms.

4. There should not be any change on fiscal year of the selected firms.

5. All necessary information must be available.

6. Any firm with significant change on two consecutive years on financial information is deleted for our list.

There are three hypotheses associated with the proposed study of this paper as follows,

1. General administration costs (SGA) have sticky behavior towards sales revenue.

2. The cost of production has sticky behavior towards sales revenue.

3. The cost of production has more sticky behavior compared with SGA. 
The proposed study uses the following two regression models for testing the hypotheses of the survey.

$$
\begin{aligned}
& \log \left(\frac{\text { SGA }_{i, t}}{\text { SGA }_{i, t-1}}\right)=\alpha_{0}+\alpha_{1} \log \left(\frac{\text { sales }_{i, t}}{\text { sales }_{i, t-1}}\right)+\alpha_{2} \cdot D \cdot \log \left(\frac{\text { sales }_{i, t}}{\text { sales }_{i, t-1}}\right), \\
& \log \left(\frac{\text { cost }_{i, t}}{\text { cost }_{i, t-1}}\right)=\beta_{0}+\beta_{1} \log \left(\frac{\text { sales }_{i, t}}{\text { sales }_{i, t-1}}\right)+\beta_{2} \cdot D \cdot \log \left(\frac{\text { sales }_{i, t}}{\text { sales }_{i, t-1}}\right),
\end{aligned}
$$

where $S G A_{i, t}$ and $S G A_{i, t-1}$ determine sales general administration expenses at time $t$ and $t-1$, respectively. In addition, sales $s_{i, t}$ and sales $s_{i, t-1}$ determine sales revenue at time $t$ and $t-1$, respectively. Finally, $D$ is a dummy variable, which is equal to 0 if there is an increase on sales figures from period $t-1$ to $t$, and 1 , otherwise.

For testing the first hypothesis of the survey, we consider the following,

$\left\{\mathrm{H}_{0}: \alpha_{1} \leq \alpha_{1}+\alpha_{2}\right.$

$\left\{\mathrm{H}_{1}: \alpha_{1}>\alpha_{1}+\alpha_{2}\right.$

In addition, to test the second hypothesis of the survey, we consider the following,

$\left\{\mathrm{H}_{0}: \beta_{1} \leq \beta_{1}+\beta_{2}\right.$

$\left\{\mathrm{H}_{1}: \beta_{1}>\beta_{1}+\beta_{2}\right.$

Finally, to examine the third hypothesis of the survey, consider the following,

$\left\{\mathrm{H}_{0}:-\beta_{2} \leq-\alpha_{2}\right.$

$\left\{\mathrm{H}_{1}:-\beta_{2}>-\alpha_{2}\right.$

Table 1 demonstrates the summary of some basic statistical observations.

\section{Table 1}

The summary of some basic statistics

\begin{tabular}{lcccc}
\hline & $\log \left(\frac{S G A_{i, t}}{S G A_{i, t-1}}\right)$ & $\log \left(\frac{\text { sales }_{i, t}}{\text { sales }_{i, t-1}}\right)$ & $\log \left(\frac{D_{i, t}}{D_{i, t-1}}\right)$ & $\log \left(\frac{\operatorname{cost}_{i, t}}{\text { cost }_{i, t-1}}\right)$ \\
\hline No. of observations & 700 & 700 & 700 & 700 \\
Mean & 0.0734 & 0.0725 & -0.019 & 0.0799 \\
Median & .0674 & .0736 & .000 & 0.0776 \\
Mode & -.89 & -.67 & .00 & -.65 \\
\hline Standard deviation & .15608 & .13331 & .06924 & .13438 \\
Variance & .024 & .018 & .005 & .018 \\
Min & -.89 & -.67 & -.67 & -.65 \\
\hline Max & 1.25 & .94 & .00 & 1.06 \\
\hline Total & 51.39 & 50.75 & -13.30 & 55.95 \\
\hline
\end{tabular}

Next, we present details of our findings on testing various hypotheses of the survey.

\section{The results}

In this section, we present details of our findings on testing various hypotheses of the survey. 
The first hypothesis of this survey is associated with the sticky behavior between SGA and sales revenue. To examine this hypothesis, we perform a regression analysis on Eq. (1) and the results are summarized in Table 2 as follows.

Table 2

The summary of ANOVA test as well as other statistics for the first regression model

\begin{tabular}{ccccccc}
\hline & Model & Sum of Squares & Df & Mean Squares & F-Value & Sig. \\
\hline \multirow{2}{*}{1} & Regression & 245.316 & 2 & 122.658 & 27.692 & 0.000 \\
& Residual & 3087.314 & 698 & 4.429 & & \\
& Total & 3332.63 & 700 & & \multirow{2}{*}{ Durbin-Watson } \\
\hline \multirow{2}{*}{ Correlation ratio } & Coefficient of & Adjusted & \multirow{2}{*}{ Error } & 2.014 \\
\hline
\end{tabular}

As we can observe from the results of Table 2, F-value is within an acceptable value, which means there is a linear relationship between dependent variable and independent variables. In addition, Durbin-Watson is equal to 2.014 , which means there is no correlation between residuals. Table 3 presents details of our regression analysis.

Table 3

The summary of regression analysis on Eq. (1)

\begin{tabular}{|c|c|c|c|c|c|}
\hline \multirow{2}{*}{ Variable } & \multicolumn{2}{|c|}{ Non-standard value } & \multirow{2}{*}{$\begin{array}{c}\text { Standard value } \\
\boldsymbol{\alpha}\end{array}$} & \multirow{2}{*}{ t-value } & \multirow{2}{*}{ Sig } \\
\hline & $\alpha$ & Standard error & & & \\
\hline (Constant) & -5.86 & 0.123 & & -47.731 & 0 \\
\hline $\log \left(\frac{\text { sales }_{i, t}}{\text { sales }_{i, t-1}}\right)$ & 6.483 & 0.871 & 0.396 & 7.442 & 0 \\
\hline $\mathrm{D}$ & -6.015 & 1.102 & -0.29 & -5.495 & 0 \\
\hline
\end{tabular}

Based on the results of Table 3, we understand that an increase of one percent on sales revenue will increase SGA expenses by $39.6 \%$. In addition, the second coefficient, $\alpha_{2}$, is negative, which indicates sticky behavior of SGA since $\alpha_{1}>\alpha_{1}+\alpha_{2}$. This means that a decrease of one percent in sales revenue will reduce $39 \%-29 \%=10 \%$ in SGA and this confirms the first hypothesis of this survey. The results of our findings are consistent with findings of Anderson et al. (2003) and Medeiros and Costa (2004).

\subsection{The Second hypothesis: Investigating sticky behavior between cost and sales revenue}

The second hypothesis of this survey is associated with the sticky behavior between cost of production and sales revenue. To examine this hypothesis, we perform a regression analysis on Eq. (2) and the results of statistical observations are summarized in Table 4 as follows.

\section{Table 2}

The summary of ANOVA test as well as other statistics for the second regression model

\begin{tabular}{ccccccc}
\hline \multicolumn{2}{c}{ Model } & Sum of Squares & Df & Mean Squares & F-Value & Sig. \\
\hline \multirow{2}{*}{2} & Regression & 1139.327 & 2 & 569.664 & 218.187 & 0.000 \\
& Residual & 1819.792 & 698 & 2.611 & & \\
& Total & 2959.12 & 700 & & \multirow{2}{*}{ Durbin-Watson } \\
& \multirow{2}{*}{ Correlation ratio } & $\begin{array}{c}\text { Coefficient of } \\
\text { determination }\end{array}$ & $\begin{array}{c}\text { Adjusted } \\
\text { coefficient }\end{array}$ & Error & 1.61583 & 2.086 \\
\hline
\end{tabular}


As we can observe from the results of Table 4, F-value is within an acceptable value, which means there is a linear relationship between dependent variable and independent variables. In addition, Durbin-Watson is equal to 2.086 , which means there is no correlation between residuals. Table 5 presents details of our regression analysis.

Table 5

The summary of regression analysis on Eq. (2)

\begin{tabular}{cccccc}
\hline \multirow{2}{*}{ Variable } & \multicolumn{2}{c}{ Non-standard value } & Standard value & \multirow{2}{*}{ t-value } & Sig. \\
\hline (Constant) & $\beta$ & Standard error & $\beta$ & -70.65 & 0.00 \\
$\log \left(\frac{\text { sales }_{i, t}}{\text { sales }_{i, t-1}}\right)$ & -6.659 & 0.094 & & & \\
D & 13.635 & 0.669 & 0.883 & 20.388 & 0.00 \\
\hline
\end{tabular}

Based on the results of Table 5, an increase of one percent will increase the cost of sold products by $88.3 \%$ while a reduction of one percent in cost of products will reduce the cost of sold products by $(88.3 \%-77.8 \%=10.5 \%)$, which indicates the sticky behavior and therefore we could confirm the second hypothesis of the survey. The results of our findings are consistent with findings of Anderson et al. (2003), Medeiros and Costa (2004) and Calleja et al. (2006). In addition, based on the results of Table 3 and Table 5, the effects of sticky for SGA and cost of products are $-29 \%$ and $77.8 \%$, respectively, which confirms the third hypothesis of the survey.

\section{Conclusion}

In this paper, we have presented an empirical investigation to learn about the sticky effects between SGA as well as cost of products and sales revenue among 70 selected firms from Tehran Stock Exchange. The proposed study of this paper has concluded that there were indeed some sticky effects between different components and sales revenue although the cost of production has shown more sticky behavior compared with SGA. The results of our findings are consistent with findings of Anderson et al. (2003), Medeiros and Costa (2004) and Calleja et al. (2006).

\section{Acknowledgement}

The authors would like to thank the anonymous referees for constructive comments on earlier version of this paper.

\section{References}

Anderson, M.C., Banker, R., \& Janakiraman, S. (2003). Are selling, general and administrative cost sticky?. Journal of Accounting Research, 41(1), 47-63.

Anderson, M., Banker, R., Huang, R., \& Janakiraman, S. (2007). Cost behavior and fundamental analysis of SG\&A costs. Journal of Accounting, Auditing \& Finance, 22(1), 1-28.

Balakrishnan, R., \& Gruca, T. S. (2008). Cost stickiness and core competency: A Note. Contemporary Accounting Research, 25(4), 993-1006.

Banker, R. D., \& Chen, L. (2006). Predicting earnings using a model based on cost variability and cost stickiness. The Accounting Review, 81(2), 285-307.

Calleja, K., Steliaros, M., \& Thomas, D. (2006). A note on cost stickiness: Some international comparisons. Management Accounting Research, 17(2), 127-140.

Chen, C. X., Lu, H., \& Sougiannis, T. (2012). The agency problem, corporate governance, and the asymmetrical behavior of selling, general, and administrative costs. Contemporary Accounting Research, 29(1), 252-282. 
Davis, M. C., \& Hamilton, J. D. (2003). Why are prices sticky? The dynamics of wholesale gasoline prices (No. w9741). National Bureau of Economic Research.

He, D., Teruya, J., \& Shimizu, T. (2010). Sticky selling, general, and administrative cost behavior and its changes in Japan. Global Journal of Business Research, 4(4), 1-10.

Medeiros O.R, \& Costa P.S. (2004). Cost stickiness in Brazilian firms. Available at SSRN: http://ssrn.com/abstract $=632365$.

Noreen, E., \& Soderstrom, N. (1997). The accuracy of proportional cost models: evidence from hospital service departments. Review of Accounting Studies,2(1), 89-114.

Weiss, D. (2010). Cost behavior and analysts' earnings forecasts. The Accounting Review, 85(4), 1441-1471. 